\title{
O EMPRESARIADO COMO ATOR POLÍTICO NO BRASIL: BALANÇO DALITERATURAE AGENDA DE PESQUISA
}

\author{
Wagner Pralon Mancuso
}

\begin{abstract}
RESUMO
Este artigo apresenta, em primeiro lugar, um balanço da produção acadêmica sobre o empresariado como ator político no Brasil. A idéia é argumentar que, desde a década de 1950 até hoje, uma parte importante desta literatura estrutura-se em torno de um debate fundamental: o empresariado que opera no Brasil é um ator político "forte" ou "fraco"? Em segundo lugar, este artigo propõe uma agenda de pesquisas sobre o tema. Para isto, levanta questões que, tomadas em conjunto, formam um roteiro abrangente para o estudo da matéria. A exposição do roteiro servirá para identificar elementos que podem ser explorados pela comunidade de cientistas sociais interessados no assunto em destaque.
\end{abstract}

PALAVRAS-CHAVE: empresariado; burguesia; poder; corporativismo.

\section{INTRODUÇÃO}

É vasta a produção acadêmica sobre o empresariado como ator político no Brasil. Há décadas, o tema tem sido objeto de artigos, dissertações, teses e livros publicados por cientistas sociais brasileiros e estrangeiros. Trabalhos sobre a matéria têm sido apresentados com freqüência em eventos, como os encontros anuais da Associação Nacional de Pós-Graduação e Pesquisa em Ciências Sociais (Anpocs) e os encontros bianuais da Associação Brasileira de Ciência Política (ABCP). O workshop "Empresa, Empresários e Sociedade”, que já foi realizado cinco vezes em diversas universidades do país, é um evento bianual dedicado exclusivamente ao estudo do empresariado, no qual são apresentadas dezenas de trabalhos sobre o assunto, muitos deles focalizando a ação política deste importante segmento social.

A proposta deste artigo, diante de tal produção acadêmica, é realizar uma dupla tarefa: em primeiro lugar, apresentar um balanço da literatura sobre o tema; em segundo lugar, propor uma agenda de pesquisas sobre a atuação política do empresariado no Brasil.

A primeira seção do artigo apresenta o balanço da literatura. A idéia é argumentar que, desde a década de 1950 até hoje, uma parte importante desta literatura estrutura-se em torno de um debate fundamental: o empresariado que opera no
Brasil é um ator político "forte” ou "fraco”?

A segunda seção do artigo levanta questões que, tomadas em conjunto, formam um roteiro abrangente para o estudo do empresariado como ator político. A exposição do roteiro servirá para identificar elementos que podem ser explorados pela comunidade de cientistas sociais interessados na temática em destaque.

\section{UM BALANÇO DA LITERATURA}

O trabalho diário da mídia mostra que, em diversas esferas e instâncias, o poder público brasileiro é permeável a pressões empresariais pontuais em defesa de benefícios particulares, por meio de corrupção, rent seeking ${ }^{1}$ etc. Não é nesse sentido particular que a literatura tem divergido historicamente acerca da força do empresariado como ator político no Brasil. Ao contrário, existe um amplo consenso em torno deste diagnóstico.

A divergência instala-se a partir do momento em que um ator político "forte" é definido como aquele cujos interesses coletivos são refletidos sistematicamente pelas decisões não-ilegais do poder público. Argumentamos que é possível identificar cinco “ondas” de trabalhos na literatura, des-

1 “Rent seeking é o uso de recursos por um ator para obter privilégios especiais por meio do processo político. O ganho obtido pelo ator é menor do que o prejuízo resultante para a sociedade” (TULLOCK, 1993). 
de a década de 1950 até os dias de hoje - a visão predominante sobre a força política do empresariado nas obras que formam uma onda é questionada pela visão prevalecente nas obras que compõem a onda posterior (ver Tabela 1$)^{2}$.

É importante estabelecer, desde logo, que o presente artigo não pretende cobrir toda a literatura relevante sobre o empresariado como ator político no Brasil. O balanço da produção acadêmica apresentado aqui é feito a partir de um "fio condutor" estabelecido previamente: o debate sobre o grau de "força" política do empresariado no país. Portanto, as obras que não estão ligadas diretamente a este debate não são tratadas neste artigo. Este propõe uma linha de interpretação da literatura sobre o tema. Outras linhas de interpretação diferentes podem ser propostas.

TABELA 1 - ONDAS, TEMAS E AUTORES

\begin{tabular}{|c|c|c|c|c|}
\hline PRIMEIRA OIIDA & SEGUIDA OIID A & TERCEIRA OIIDA & QUARTA OIIDA & QUIITA OIIDA \\
\hline $\begin{array}{c}\text { DÉCADA DE } 1950 \text { E } \\
\text { PR IMEIRA METADE } \\
\text { D A DÉ CADA DE } \\
1960\end{array}$ & $\begin{array}{c}\text { DÉCADAS DE } 1960 \mathrm{E} \\
1970\end{array}$ & \begin{tabular}{|} 
SE GUIID A ME TADE \\
D A DÉ CADA DE \\
1970, DÉCADA DE \\
1980 E PRIME IRA \\
ME TADE DA \\
DÉ CAD A DE 1990
\end{tabular} & $\begin{array}{c}\text { SE GUIID A } \\
\text { MET ADE DA } \\
\text { DÉ CAD A DE } 1990 \\
\text { ATÉ HO JE }\end{array}$ & $\begin{array}{c}\text { PRIMEIRA } \\
\text { ME TADE D A } \\
\text { DÉCADA DE } 2000 \\
\text { ATÉ HOJE }\end{array}$ \\
\hline \multicolumn{5}{|c|}{ AR GUMEII TO } \\
\hline $\begin{array}{l}\text { A parcela nacionalista } \\
\text { do empresariado } \\
\text { industrial brasileiro de } \\
\text { grande porte é capaz } \\
\text { de liderar uma aliança } \\
\text { com os trabalhadores } \\
\text { pela "revoluçấo } \\
\text { nacional e } \\
\text { dem ocrática", contra } \\
\text { os interesses arcaicos } \\
\text { do latifúndio (no plano } \\
\text { interno) e do } \\
\text { im perialismo (no plano } \\
\text { externo) }\end{array}$ & $\begin{array}{c}\text { A burgue sia industrial } \\
\text { brasileira é incapaz } \\
\text { de exercer liderança, } \\
\text { porque: } \\
\text { i) é fraca; } \\
\text { ii) nẫo escolhe os } \\
\text { trabalhadores como } \\
\text { parceiros } \\
\text { preferenciais; } \\
\text { iii) nấo é contra o } \\
\text { latifúndio; } \\
\text { iv) nẫo é nacionalista; } \\
\text { v) nẫo é } \\
\text { antiimperialista; } \\
\text { vi) contenta-se em ser } \\
\text { a sócia menor da } \\
\text { aliança tríplice que, } \\
\text { além dela, tam bém } \\
\text { envolve o estado e o } \\
\text { capital internacional. }\end{array}$ & $\begin{array}{c}\text { a) Com a campanha } \\
\text { contra a estatizaçấo } \\
\text { (meados dos anos de } \\
1970 \text { ) e com a } \\
\text { campanha pela } \\
\text { redemocratizaçẫo (final } \\
\text { dos anos de 1970), o } \\
\text { grande em presariado } \\
\text { brasileiro rompe com o } \\
\text { bloco que subiu ao } \\
\text { poder em } 1964 \text {. } \\
\text { b) Apesar de seus } \\
\text { limites, a burguesia } \\
\text { industrial brasileira } \\
\text { teve atuaçấo política } \\
\text { intensa ao longo de } \\
\text { todas as fases do } \\
\text { processo de } \\
\text { industrializaçấo, tanto } \\
\text { na vigência do regime } \\
\text { democrático quanto na } \\
\text { vigência de regimes } \\
\text { autoritários (E stado } \\
\text { Novo e ditadura } \\
\text { militar). } \\
\text { c) o grande } \\
\text { empresariado atuou } \\
\text { unido e com sucesso } \\
\text { em momentos-chave } \\
\text { como a deposiçấo de } \\
\text { Jango (1964) e a } \\
\text { Assem bléia Nacional } \\
\text { Constituinte (1987- } \\
1988 \text { ). }\end{array}$ & $\begin{array}{c}\text { O empresariado } \\
\text { que atua no Erasil } \\
\text { é incapaz de açẫo } \\
\text { coletiva, tanto no } \\
\text { âmbito intra- } \\
\text { setorial quanto no } \\
\text { âm bito } \\
\text { intersetorial. } \\
\text { Esta incapacidade } \\
\text { é a razâo de sua } \\
\text { fraqueza política. } \\
\text { A causa principal } \\
\text { da incapacidade } \\
\text { de açẫo coletiva e, } \\
\text { por conseguinte, } \\
\text { da fraqueza } \\
\text { política, é o } \\
\text { sisterna } \\
\text { corporativista de } \\
\text { representaçẫo de } \\
\text { interesses. }\end{array}$ & $\begin{array}{c}\text { O empresariado } \\
\text { empenhou-se em } \\
\text { um grande processo } \\
\text { de organizaçấo e } \\
\text { mobilizaçấo ao } \\
\text { longo da década de } \\
1990 . \\
\text { E sta açấo } \\
\text { empresarial teve } \\
\text { desdobram entos no } \\
\text { plano dom éstico- } \\
\text { por exemplo, a } \\
\text { campanha pela } \\
\text { reduçẫo do dusto } \\
\text { Erasil; e no plano } \\
\text { internacional - por } \\
\text { exemplo, com a } \\
\text { criaçẫo da Coalizấo } \\
\text { Empresarial } \\
\text { Erasileira." } \\
\text { A iniciativa dos } \\
\text { exemplos } \\
\text { mencionados partiu } \\
\text { exatamente de uma } \\
\text { entidade setorial de } \\
\text { cúpula do sistema } \\
\text { corporativista: } \\
\text { a Con federaçấo } \\
\text { Nacional da } \\
\text { Indústria. }\end{array}$ \\
\hline
\end{tabular}

\footnotetext{
$\overline{2} \mathrm{O}$ insight para essa abordagem à literatura ocorreu durante a argüição da Professora Eli Diniz na defesa pública de minha tese de doutorado, em outubro de 2004. Sou-lhe grato por isso.
} 


\section{EXEMPLOS DE TRAB ALHOS REPRESEIITATIVOS}

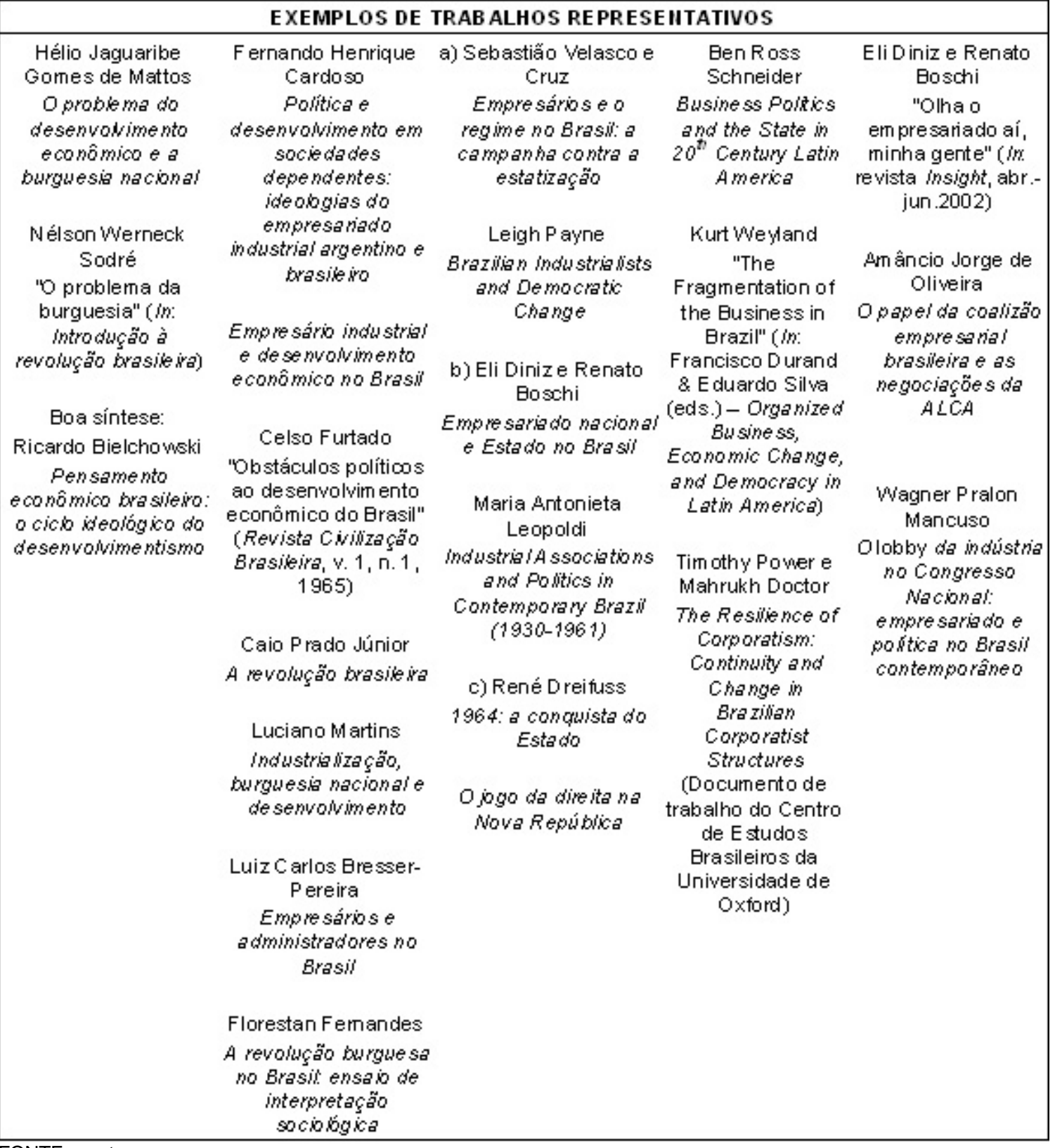

FONTE: 0 autor.

O ponto de partida adotado neste artigo é a obra de autores como Hélio Jaguaribe Gomes de Mattos (1958) e Nélson Werneck Sodré (1958), então ligados ao Instituto Superior de Estudos Brasileiros (ISEB) e que, no final dos anos de 1950 e no início dos anos de 1960, afirmavam que o empresariado industrial, de grande porte e de capital nacional, era um ator suficientemente forte para liderar uma aliança com os trabalhadores urbanos organizados pela revolução "nacional e democrática” contra o latifúndio, no plano interno, e contra o imperialismo, no plano externo.

Desde o início dos anos de 1960 (principalmente após o golpe militar de 1964) e durante toda a dé- cada de 1970, uma série de autores passou a argumentar que a aliança revolucionária defendida pelos isebianos era inviável, posto que a burguesia industrial brasileira: (i) era fraca; (ii) não desejava ter o proletariado organizado como parceiro político; (iii) não opunha-se ao latifúndio; (iv) não era nacionalista; (v) não era antiimperialista; (vi) contentava-se em ser sócia menor da aliança tríplice que, além dela, também envolvia o Estado e o capital internacional. Dentre os autores representativos desta segunda onda, destacam-se: Fernando Henrique Cardoso (1965; 1971; 1972); Celso Furtado (1965); Caio Prado Júnior (1966); Luciano Martins (1968); Luiz Carlos Bresser-Pereira (1974); 


\section{Florestan Fernandes (1976).}

Uma terceira onda de trabalhos surgiu a partir do final da década de 1970, ao longo da década de 1980 e na primeira metade da década de 1990.

Uma parte desses trabalhos focalizou a demonstração de força do grande empresariado brasileiro que, inicialmente, com a campanha contra a estatização (CRUZ, 1978) e, posteriormente, com a campanha pela redemocratização (PAYNE, 1994), iniciou e prosseguiu o rompimento com o bloco que subiu ao poder com o golpe de 1964.

Outra parte desses trabalhos sustentava que, não obstante aos inquestionáveis limites estruturais da burguesia industrial brasileira, os industriais realizaram uma atuação política intensa e, muitas vezes, bem-sucedida, ao longo de todas as fases do processo de industrialização, tanto na vigência do regime democrático quanto na vigência de regimes autoritários - Estado Novo e ditadura mili$\operatorname{tar}$ (DINIZ \& BOSCHI, 1978; LEOPOLDI, 1984). Além de vigorosa, a atuação política da indústria também foi bastante flexível, pois o setor soube utilizar-se simultaneamente dos diferentes canais disponíveis, como os órgãos de classe (ou seja, as entidades dos sistemas corporativo e extracorporativo), os "anéis burocráticos"3 e os contatos pessoais diretos com os tomadores de decisão. A criação de um sistema híbrido de representação de interesses - reforçado nas décadas de 1980 e de 1990, com formas novas de organização empresarial, como os Institutos Liberais, o Pensamento Nacional das Bases Empresariais (PNBE) e o Instituto de Estudos para o Desenvolvimento Industrial (IEDI) - foi o resultado da grande capacidade de adaptação e de inovação demonstrada pelos industriais (DINIZ \& BOSCHI, 1979; 1993; 1997; DINIZ, 1992).

Ainda outros trabalhos pertencentes à terceira onda defendiam a tese de que o grande empresariado

3 Cardoso (1975) criou o conceito de “anel burocrático” para designar uma forma de interação do setor público com o setor privado durante os governos militares. Segundo Cardoso, a burguesia industrial não participou diretamente, sob o regime militar, da "fração dirigente do topo do aparelho de Estado”, círculo restrito aos próprios militares e aos tecnoburocratas. No entanto, os grandes empresários do setor industrial participaram de decisões do Estado por meio dos “anéis burocráticos”, alianças momentâneas que os uniam a burocratas de agências governamentais e/ou a administradores de empresas públicas, em torno de questões específicas. que opera no Brasil soube atuar unido e mostrar toda sua força política em momentos-chave como a deposição do Presidente João Goulart, em 1964, para a instauração do regime militar (DREIFUSS, 1981), e a Assembléia Nacional Constituinte, em 1987 e 1988 (DREIFUSS, 1989).

As obras que formam as três primeiras ondas da literatura, cuja essência acabamos de sintetizar, são obras extremamente influentes, amplamente conhecidas e debatidas, podendo ser consideradas como estudos "clássicos", embora divergentes, sobre a temática em foco neste artigo. As obras que compõem as duas últimas ondas da literatura são mais recentes, menos conhecidas, por isso, dedicaremos um espaço maior à exposição de suas idéias centrais, bem como ao contraste entre elas.

A quarta onda de trabalhos sobre o empresariado como ator político no Brasil, formada basicamente por obras de brasilianistas, começa na segunda metade da década de 1990 e estende-se até hoje.

De fato, uma série de trabalhos recentes (SCHNEIDER, 1997a; 1997b; 1998; 2002; 2004; WEYLAND, 1998a; 1998b; 2001; KINGSTONE, 2001; DOCTOR, 2002; POWER \& DOCTOR, 2002) afirma que, no Brasil, o empresariado apresenta uma dificuldade crônica de constituir e manter ações coletivas em torno de propostas unificantes $^{4}$, tanto em âmbito intra-setorial (isto é, em cada setor da economia, tomado separadamente) quanto em âmbito intersetorial (isto é, no caso dos diferentes setores da economia, tomados como um todo) ${ }^{5}$.

Essa deficiência de ação coletiva seria a causa principal da fraqueza política do empresariado no Brasil, ou seja, de sua incapacidade de influenciar o poder público para tomar decisões abrangentes que favoreceriam a operação da iniciativa privada no país. A fraqueza política do empresariado, por sua vez, o incapacitaria a exercer o papel de liderança

4 Como veremos adiante, as propostas unificantes têm duas características essenciais. Em primeiro lugar, despertam elevado grau de interesse em grande quantidade de empresas. Em segundo lugar, criam forte convergência entre as empresas interessadas - seja a favor das propostas, seja contra elas (SMITH, 2000).

5 Neste artigo, a expressão “setor econômico” designa a área geral de atuação de uma empresa (por exemplo: indústria, comércio, agricultura, transporte) e a expressão “cate- 
que deveria assumir, principalmente, a partir do momento em que o antigo modelo de desenvolvimento liderado pelo Estado entrou em crise e em que um novo modelo de desenvolvimento emergiu em seu lugar, modelo em que o papel de protagonista é reservado para a iniciativa privada.

Os defensores da tese da fraqueza política são unânimes em atribuir ao sistema corporativista de representação de interesses, em grande medida, a responsabilidade pela mencionada deficiência de ação coletiva e, como conseqüência, pela própria debilidade política.

Em que consiste, porém, o sistema chamado de corporativista? Esse sistema foi instituído no Brasil pela legislação sindical da década de 1930, sob o governo de Getúlio Vargas, como o sistema oficial para a intermediação dos interesses dos atores emergentes no novo cenário político do país os empresários e os trabalhadores urbanos. Criado há mais de 70 anos, o sistema corporativista subsiste até hoje, tendo passado por modificações importantes, sem, no entanto, ter perdido seus traços fundamentais. No que tange às alterações, a constituição de 1988 suprimiu os mecanismos que, ao longo do período anterior, permitiram que o governo federal exercesse controle direto sobre o sistema corporativista, como a exigência de autorização prévia para a fundação de sindicatos, o poder de intervir nas eleições para postos de liderança e a faculdade de interferir no funcionamento cotidiano das entidades. As mudanças trazidas pela constituição de 1988 resultaram, portanto, na ampliação da autonomia das entidades do sistema corporativo. Por outro lado, a constituição manteve a unicidade sindical e a contribuição sindical. A manutenção destes dois institutos explica a sobrevivência da estrutura corporativista até os nossos dias.

No que diz respeito à organização do empresariado, a unicidade sindical consiste em atribuir a somente um sindicato patronal o status de representante oficial dos interesses das firmas que realizam atividades econômicas idênticas, similares ou conexas - constituindo assim uma

goria de atividade econômica” designa o segmento específico do setor em que uma empresa atua (por exemplo: indústria automobilística, indústria de alimentos, indústria de bebidas, dentre outros; comércio atacadista, comércio varejista, dentre outros; agricultura de café, agricultura de soja, agricultura de cana-de-açúcar, dentre outros; transporte rodoviário de carga, transporte rodoviário de passageiros, dentre outros). mesma categoria econômica - e que estão situadas na região abarcada pela entidade ${ }^{6}$. Os sindicatos patronais podem ter abrangência municipal, intermunicipal, estadual, interestadual ou nacional. Eles formam o alicerce da estrutura corporativista, que é composta ainda por organizações de grau superior. Na esfera imediatamente superior à dos sindicatos, estão as federações, que reúnem sindicatos de empresas que atuam na mesma categoria ou no mesmo setor. Na cúpula da estrutura corporativa, situam-se as confederações, que reúnem federações empresariais.

A filiação das empresas aos sindicatos patronais é voluntária. Filiando-se a eles, as empresas habilitam-se a receber os serviços que as entidades prestam exclusivamente aos associados. Entretanto, o pagamento da contribuição sindical amplamente conhecida como "imposto sindical" - não é voluntário, uma vez que é devido por todas as empresas aos sindicatos que as representam. A contribuição sindical devida pelas empresas varia conforme o capital que possuem. A contribuição sindical responde pela sustentação financeira de todos os níveis da estrutura corporativista, uma vez que a contribuição paga por uma empresa é distribuída entre o sindicato (60\%), a federação (15\%) e a confederação (5\%) que a representam. Os 20\% restantes vão para a "Conta Especial Emprego e Salário” do governo federal.

Segundo os expoentes da tese da fraqueza política, as regras do sistema corporativista dificultam a ação coletiva do empresariado em torno de propostas unificantes por duas razões: (i) porque engendram entidades setoriais de grau superior, cujos líderes não são representativos e (ii) porque não prevêem uma entidade de cúpula multissetorial.

Por que líderes de pouca ou nenhuma expressão chegam a ser escolhidos pelas entidades setoriais de grau superior? Porque, graças à legislação corporativista, associações de grau inferior que possuem importância econômica muito diferente, de fato, obtêm importância equivalente, de jure, na vida política interna das associações de grau superior. Ou seja, nos processos eleitorais das associações de grau superior, a legislação corporativista iguala o peso de associações eco-

\footnotetext{
6 A unicidade sindical é garantida pelo artigo $8^{\circ}$, inciso II, da Constituição brasileira. As regras que regem a organização sindical no Brasil estão reunidas sob o título V (artigos 511-610) da Consolidação das Leis do Trabalho (CLT).
} 
nomicamente pouco relevantes ao peso de associações economicamente mais expressivas. Deste modo, por exemplo, na eleição dos líderes das confederações setoriais nacionais, as federações de estados menos importantes para o setor representado - que são numerosos - possuem peso equiparável ao peso das federações dos estados mais importantes - que são poucos. O mesmo ocorre, antes, na eleição dos líderes das próprias federações estaduais, em que sindicatos de municípios e categorias econômicas de pequena importância relativa - que são muitos - têm o mesmo peso que os sindicatos de municípios e categorias econômicas mais importantes - que são poucos. Assim, a escolha para a liderança das entidades nacionais geralmente recai sobre empresários de pequeno porte, que atuam em categorias econômicas de importância marginal, e que provêm de estados e regiões menos desenvolvidas, em vez de incidir sobre os principais empresários das categorias econômicas mais pujantes e dos estados e regiões mais desenvolvidos do país. Estes líderes eleitos, de pouca expressão, não precisam esforçar-se para atrair, conquistar e manter membros ativos e contribuintes para a entidade, posto que, como foi visto acima, a manutenção financeira da entidade já está assegurada pelo imposto sindical, outra regra do sistema. Desta forma, a distorção introduzida pela legislação corporativista exerce um efeito direto e negativo sobre a representatividade dos líderes das entidades nacionais, justamente porque os empresários mais importantes não se vêem representados naqueles líderes. A falta de representatividade dos líderes das entidades nacionais do sistema corporativista patronal reduziria a credibilidade, a importância e a eficácia dessas entidades como organizadoras da ação coletiva em torno de demandas unificantes na esfera intra-setorial.

Os autores também apontam que a legislação corporativista não prevê a criação de uma entidade multissetorial de cúpula. Essa entidade poderia ser o fórum adequado para a formação de consensos em torno de políticas públicas capazes de tornar a economia nacional mais eficiente. A entidade poderia servir ainda como contrapeso à busca de interesses setoriais exclusivos, assim como poderia servir para potencializar o poder da ação política do empresariado. Entretanto, uma tal entidade não existe. $\mathrm{E}$ a inexistência de uma entidade multissetorial de cúpula indica, para aqueles autores, que o empresariado brasileiro, como um todo, é desarticulado. Esta desarticulação reitera, portanto, a incapacidade empresarial de ação coletiva em torno de demandas unificantes, agora, de maneira intersetorial.

A quinta e a última ondas abrangem trabalhos publicados ao longo da década de 2000 (OLIVEIRA, 2003; MANCUSO, 2004; 2007; MANCUSO \& OLIVEIRA, 2006). Esses trabalhos colocam em questão algumas idéias centrais das obras que formam a onda anterior: em primeiro lugar, a idéia de que o empresariado no Brasil é incapaz de ação coletiva; em segundo lugar, a idéia de que o corporativismo é a causa principal desta incapacidade.

Os trabalhos da quinta onda mostram que o empresariado que atua no Brasil, efetivamente, empenhou-se em um notável processo de organização e de mobilização ao longo da década de 1990. Essa ação coletiva decorreu da confluência de um processo de natureza econômica e outro processo de natureza política ${ }^{7}$.

No que se refere ao processo de natureza econômica, é importante levar em conta que a década de 1990 acarretou uma profunda mudança no ambiente em que o empresariado atuava no Brasil. A causa dessa mudança foi a inflexão liberal na política de estabilização econômica do país, cuja implementação remonta ao início do governo Collor (1990), e teve como objetivo enfrentar a crise que atingiu o Brasil desde o começo da década de 1980 até a primeira metade da década de 1990, tendo a inflação descontrolada como sintoma mais notável.

Um elemento-chave da inflexão liberal foi a ampliação da abertura da economia brasileira ao comércio internacional, processo que envolveu dois movimentos concomitantes. O primeiro foi um movimento de abertura "para dentro", que resultou em grande expansão da concorrência no mercado interno, em decorrência do crescimento do volume de produtos importados. Tal crescimento foi favorecido pela queda de barreiras tarifárias e não-tarifárias às importações, assim como pela sobrevalorização do real, que persistiu desde a implantação da nova moeda, em meados de 1994, até o princípio de 1999. O outro movimento foi de abertura "para fora”, marcado pela

7 Este parágrafo e os seguintes são baseados em Mancuso (2007) e Mancuso e Oliveira (2006). 
meta de conquistar mercados novos no exterior. "Exportar ou morrer": assim o Presidente Fernando Henrique Cardoso expressou essa meta, de forma lapidar, no discurso de posse de Sérgio Amaral como Ministro do Desenvolvimento, da indústria e do comércio exterior, em meados de seu segundo governo.

A década de 1990 também foi marcada pelo envolvimento do Brasil em vários processos de negociações internacionais, dentre os quais destaca-se o processo de negociação da Área de Livre Comércio das Américas (ALCA). Se aprovada, a ALCA significaria um segundo choque de liberalização comercial, cujo impacto dificilmente pode ser subestimado.

Esses eventos de natureza econômica - a abertura comercial efetivamente realizada e a perspectiva de uma abertura ainda maior, por meio de negociações internacionais, sobretudo a da Alca - tiveram importância fundamental para despertar um grande processo de organização e mobilização política do empresariado brasileiro. No plano interno, o desafio da concorrência erigiu a competitividade ao patamar de objetivo prioritário a ser perseguido pelas empresas. Assim, a redução do custo Brasil tornou-se a bandeira sob a qual o empresariado congregou-se. Custo Brasil é a expressão que passou a resumir o conjunto de fatores que prejudicam a competitividade das empresas do país diante de empresas situadas em outros países. No plano externo, o empresariado criou a Coalizão Empresarial Brasileira (CEB), entidade multissetorial formada para participar de processos de negociação internacional em curso - como foi o caso da Alca. Entretanto, o processo de organização e mobilização do empresariado brasileiro na década de 1990 não deve ser interpretado como um desdobramento espontâneo do processo de natureza econômica. O processo econômico pode ser tomado como uma causa necessária, mas não suficiente, para a referida mudança de postura do empresariado. É preciso destacar também a ação política intencional, que permitiu os avanços em termos de organização e mobilização.

A Confederação Nacional da Indústria (CNI) exerceu um papel central de liderança política na organização e mobilização do empresariado, tanto no movimento pela redução do custo Brasil quanto na criação da CEB. Além de intensa, a mobilização empresarial obteve um índice elevado de sucesso político (OLIVEIRA, 2003;
MANCUSO, 2004; 2007). Ora, a CNI é a entidade de cúpula do sistema corporativista de representação dos interesses da indústria. Curioso é que justamente o corporativismo é tido pelos autores da quarta onda como o maior responsável pela suposta incapacidade de ação coletiva do empresariado do país, tanto no plano intra-setorial quanto no plano intersetorial.

Os trabalhos da quinta onda mostram que a iniciativa da CNI ocorreu mesmo sem ter havido qualquer mudança significativa no modelo de funcionamento do sistema corporativista de representação de interesses. A mudança que aconteceu foi uma mudança de contexto, posto que a vigência de um ambiente empresarial mais competitivo, em função da abertura econômica, serviu como fator indutor da mobilização em relação ao tema do custo Brasil. A perspectiva de um aprofundamento ainda maior da abertura comercial desenhava-se com as negociações da ALCA. Diante da mudança de contexto e dispondo dos recursos procedentes dos pilares tradicionais do sistema, a estrutura corporativista mostrou-se capaz de assumir o papel do "empreendedor político" - ou seja, o ator que decide, por conta própria, assumir o custo necessário para deflagrar e organizar a ação coletiva, com vistas à provisão do benefício desejado por todos (HARDIN, 1982; MOE, 1988).

\section{UM ROTEIRO PARA PESQUISAS}

É muito amplo o campo aberto para os pesquisadores interessados em contribuir para o estudo do empresariado como ator político no Brasil. Nesta seção, levantamos sete questões fundamentais que formam um roteiro para o estudo da matéria. As questões apresentadas a seguir admitem uma grande variedade de respostas, como ilustra a Tabela 2 . As respostas dadas às questões ajudam a definir o perfil da pesquisa a ser realizada. Uma pesquisa pode levar em conta todas as questões ou apenas algumas delas. As questões são compatíveis com diversos recortes históricos, diferentes abordagens teóricas e opções metodológicas variadas. Assim como o balanço da literatura realizado na seção anterior, este roteiro não é completamente exaustivo. É possível traçar roteiros alternativos, formados por questões diferentes.

A idéia da seção é definir uma agenda de pesquisa, apontando caminhos que poderiam ser trilhados por estudiosos dedicados ao tema. O trabalho de vários pesquisadores ao longo desses caminhos permitirá o acúmulo de conhecimento 
sobre a ação política do empresariado no país.

As questões são as seguintes:

1) Quais são os atores focalizados?

2) Quais são os alvos desses atores?

3) Que decisões despertam o interesse desses atores?

4) Em que momentos ocorre a atuação política?

5) Qual é a forma da atuação política?

6) Quais são os fins da atuação política?

7) Quais são os resultados da atuação políti$\mathrm{ca}$ ?

\section{III.1. Atores}

A primeira coluna da Tabela 2 apresenta cinco critérios que ajudam a definir, com precisão, o(s) ator(es) focalizado(s) nas pesquisas.

Um critério é o número de atores. A ação política empresarial pode ser exercida por vários atores, desde o indivíduo isolado até as mais diversas espécies de coletividade. A grande maioria dos trabalhos sobre o tema tem focalizado a ação po- lítica de conjuntos de empresários. Há um grande espaço para pesquisas que estudem em profundidade as atividades políticas desempenhadas por empresas tomadas individualmente (por exemplo, uma pesquisa sobre as atividades desempenhadas por empresas como a AmBev, a Souza Cruz etc.).

Outro critério é a área de atuação. É muito importante que as pesquisas cubram a ação política de empreendedores que realizam as mais diversas atividades. As pesquisas podem abordar, por exemplo, a mobilização política de empresas que pertencem aos mesmos setor e categoria econômica (por exemplo, industriais do ramo têxtil, agricultores de cana-de-açúcar, transportadores aéreos de passageiros etc.). Outras pesquisas podem tratar da atuação política de empresas pertencentes ao mesmo setor, mas a categorias econômicas diferentes (por exemplo, industriais de todos os elos da cadeia produtiva de veículos automotores; transportadores de passageiros e de cargas por via terrestre etc.). Os trabalhos podem analisar ainda a ação política coletiva de empresas ligadas a setores econômicos diversos (por exemplo, a união em defesa da reforma tributária de empresários dos setores industrial, comercial, agrícola, financeiro e de transportes, dentre outros).

TABELA2 - QUESTÕES ANALÍTICAS

\begin{tabular}{|c|c|c|c|c|c|c|}
\hline ATORES & ALVOS & DECISÖES & $\begin{array}{c}\text { MOME IITO DE } \\
\text { ATUAÇÄ́O }\end{array}$ & $\begin{array}{l}\text { FORMA DE } \\
\text { ATUAÇÄ́O }\end{array}$ & $\begin{array}{c}\text { FIMDA } \\
\text { ATUAÇÄ́o }\end{array}$ & $\begin{array}{l}\text { RESULTADO DA } \\
\text { ATUAÇAO }\end{array}$ \\
\hline $\begin{array}{l}\text { Número } \\
\text { Um } \\
\text { Mais de um }\end{array}$ & $\begin{array}{l}\text { Setor público } \\
\text { nacional: } \\
\text { federal, } \\
\text { estaduale } \\
\text { municipal }\end{array}$ & $\begin{array}{l}\text { Irteresses } \\
\text { semelhantes }\end{array}$ & \multirow{4}{*}{$\begin{array}{l}\text { Escolha dos } \\
\text { tom dores de } \\
\text { dedisoses }\end{array}$} & \multirow{4}{*}{ Ĺcita ou ilícita } & \multirow{4}{*}{$\begin{array}{l}\text { Mudar, tanto } \\
\text { quanto } \\
\text { possivel, o } \\
\text { status quo para } \\
\text { melhor }\end{array}$} & Ganho \\
\hline $\begin{array}{l}\text { Área de atuaçấo } \\
\text { Mesmo setor, } \\
\text { mesma categoria }\end{array}$ & $\begin{array}{l}\text { Exedutivo } \\
\text { Legisativo } \\
\text { Judiciário }\end{array}$ & & & & & \multirow{3}{*}{ Perda } \\
\hline $\begin{array}{l}\text { Mesmo setor, } \\
\text { categorias } \\
\text { diferentes } \\
\text { Setores } \\
\text { diferentes } \\
\end{array}$ & \multirow{3}{*}{$\begin{array}{l}\text { Setor público } \\
\text { estrangeiro }\end{array}$} & \multirow{3}{*}{$\begin{array}{c}\text { Irteresses } \\
\text { diferentese } \\
\text { nấo conflitantes }\end{array}$} & & & & \\
\hline Localizaçẫo & & & & & & \\
\hline $\begin{array}{l}\text { Municipal } \\
\text { Intemunicipal } \\
\text { Estadual } \\
\text { Interestadual } \\
\text { Nacional }\end{array}$ & & & \multirow[t]{2}{*}{$\begin{array}{l}\text { E stágios do } \\
\text { ciclo decisório }\end{array}$} & \multirow{2}{*}{$\begin{array}{l}\text { Técnicas, } \\
\text { táticase } \\
\text { estratégias }\end{array}$} & \multirow{2}{*}{$\begin{array}{c}\text { Impedir, tanto } \\
\text { quanto } \\
\text { possivel, a } \\
\text { piora do status } \\
\text { quo }\end{array}$} & Alívio \\
\hline Origern do capital & $\begin{array}{c}\text { Apordose } \\
\text { órgấos } \\
\text { internacionais }\end{array}$ & $\begin{array}{l}\text { Irteresses } \\
\text { diferentese } \\
\text { confilitantes }\end{array}$ & & & & Frustraçẫo \\
\hline
\end{tabular}

FONTE: 0 autor. 
A localização geográfica é mais um critério que pode ajudar na definição dos atores a serem focalizados. Pesquisas interessantes podem ter como objeto a mobilização política de empresários situados em um mesmo município ou em municípios vizinhos (por exemplo, a mobilização empresarial em municípios de pequeno porte; a mobilização do empresariado local pela criação de consórcios intermunicipais de desenvolvimento etc.). Da mesma forma, as investigações podem abordar a atuação de empresários localizados em um mesmo estado ou região (por exemplo, a atuação empresarial com vistas à criação ou à reforma de agências regionais de desenvolvimento, como a Agência de Desenvolvimento da Amazônia (ADA) ou a Agência de Desenvolvimento do Nordeste (Adene); a atuação política dos agricultores de um estado atingido por fenômenos naturais como secas, enchentes etc.). Finalmente, a atenção pode ser dedicada ao estudo da ação política empresarial em âmbito nacional ou internacional (por exemplo, a ação de empresários de todo o país em defesa da redução das taxas de juros ou em defesa do investimento federal em infra-estrutura; a ação comparada de empresários brasileiros, argentinos, paraguaios e uruguaios interessados em processos de negociação internacional como o Mercosul etc.).

O porte das empresas também é um critério interessante para a definição dos atores estudados. Há muito espaço, por exemplo, para pesquisas sobre a organização e a luta política dos microempresários e/ou dos empresários de pequeno e médio portes. Por outro lado, pesquisas de grande relevância podem ser conduzidas sobre a mobilização política dos empresários que lideram os segmentos em que atuam. As classificações setoriais publicadas periodicamente por revistas especializadas podem ser extremamente úteis neste caso.

Finalmente, é possível mencionar o critério da origem do capital das empresas. É oportuno que desenvolvam-se pesquisas voltadas para a compreensão de como atuam politicamente, no Brasil, as empresas de capital externo, de diversas nacionalidades. A atuação política dessas empresas também pode ser analisada vis-à-vis à atuação das empresas de capital nacional.

Os critérios mencionados acima podem ser conjugados para definir ainda com mais precisão o objeto das pesquisas. Por exemplo, uma pes- quisa pode focalizar a ação política do empresariado industrial paulista de grande porte, ligado a empresas multinacionais. Outra pesquisa pode tratar da ação política, na esfera federal, das grandes redes multinacionais do setor de supermercados (Carrefour, Wal-Mart etc.). Em resumo, importa enfatizar que é vastíssimo o universo de atores empresariais, cuja mobilização política pode tornar-se matéria de investigação acadêmica. Este universo fascinante deve ser explorado em todos os seus quadrantes.

\section{III.2. Alvos}

O conjunto de decisões do setor público que são capazes de interferir sobre a atividade do setor privado é muito abrangente. A percepção de que tais decisões importam para o desempenho das empresas que comandam é o motivo que impulsiona os empresários a mobilizarem-se durante os processos decisórios, para promoverem seus interesses.

Grande parte das decisões relevantes para os empresários que operam no país é tomada pelo setor público nacional. Portanto, os pesquisadores têm um largo campo de estudo na atuação política do empresariado diante dos três poderes, nas esferas federal, estadual e local.

Há pouquíssimos trabalhos no Brasil sobre a ação empresarial diante dos poderes Executivo, Legislativo e Judiciário, tanto na esfera estadual quanto na esfera local. Assim, ainda há muito que ser feito junto aos governos estaduais e às prefeituras (seja na cúpula do governo, das secretarias, das fundações, das autarquias, das empresas públicas e das sociedades de economia mista; seja no funcionalismo de menor escalão); às assembléias legislativas e às câmaras de vereadores (no nível da Presidência, da Mesa Diretora, do Colégio de Líderes, das comissões permanentes e temporárias, de cada parlamentar e do funcionalismo das casas) e aos juizados localizados nos estados e municípios.

Comparativamente, existem mais estudos sobre a ação política do empresariado diante dos poderes Executivo e Legislativo, na esfera federal. Mesmo assim, ainda há muito espaço para investigações sobre a atuação dos empresários junto ao governo federal (novamente, tanto na cúpula da Presidência, dos ministérios, das secretarias, das fundações, das autarquias, das estatais etc., quanto no funcionalismo de menor escalão) e junto 
às Casas do Congresso Nacional (Câmara dos Deputados e Senado Federal). Um caminho promissor, e pouco explorado, é o estudo da atuação empresarial frente ao Poder Judiciário federal (por exemplo, uma pesquisa muito interessante poderia ser feita sobre as Ações Diretas de Inconstitucionalidade (Adins) propostas pelas confederações sindicais e pelas entidades de classe de âmbito nacional).

Decisões tomadas por órgãos do setor público de outros países também podem interferir sobre a atividade econômica de empresas localizadas no Brasil. É o que ocorre, por exemplo, quando interpõem-se barreiras tarifárias ou nãotarifárias às exportações nacionais. É importante desenvolver estudos sobre a mobilização empresarial que ocorre nesses casos.

Outras vezes, as decisões que afetam a atividade das empresas situadas no Brasil são tomadas em órgãos internacionais (como a Organização Mundial do Comércio) ou em acordos bilaterais ou multilaterais. Também é oportuno investigar a atuação empresarial que visa a estas decisões.

\section{III.3. Decisões}

O cientista político norte-americano Theodore Lowi (1964) mostrou que a natureza da política pública (isto é, a natureza da policy) ajuda a prever não somente a identidade e a variedade dos interesses que irão mobilizar-se no processo decisório, mas também o grau de intensidade do conflito que eventualmente prevalecerá entre os interesses envolvidos na decisão (isto é, a politics).

Lowi sugeriu que as políticas públicas podem ser classificadas, quanto à natureza, em três tipos gerais: distributivas, regulatórias e redistributivas.

As políticas distributivas favorecem clientelas específicas. Como elas são facilmente multiplicáveis, vários interesses diferentes podem ser atendidos simultaneamente. Desta forma, predomina na "arena" distributiva uma relação pouco conflituosa, de "não-interferência mútua" entre os interesses que dirigem-se aos tomadores de decisão. Inspirado na tipologia de Lowi e focalizando exclusivamente as políticas que interessam ao empresariado, Smith (2000) designou este tipo de política pública como política "particular" (particularistic issues). Políticas "particulares" provocam um alto grau de interesse no pequeno número de empresas beneficiadas e um baixo grau de interesse na maioria das outras empresas, pouco afetadas pelas decisões. Pesquisas interessantes podem ser desenvolvidas sobre a mobilização empresarial por políticas deste tipo, que despertam interesses diferentes, mas não-conflitantes (por exemplo, o lobby das empresas de uma categoria determinada por benefícios tributários exclusivos).

As políticas regulatórias estabelecem de forma clara tanto os atores favorecidos quanto os atores desfavorecidos. Elas diferem, portanto, das políticas distributivas, que estabelecem com clareza apenas os "clientes" favorecidos. A política regulatória sobre a qual Lowi mais detém-se é a política tarifária do comércio externo nos Estados Unidos, a partir de 1962, que estabelece claramente os atores prejudicados (os antigos beneficiários da distribuição “fácil” de tarifas protecionistas) e os atores favorecidos (os novos beneficiários do comércio mais livre). Ao contrário das políticas distributivas, as políticas regulatórias tendem a gerar relações conflituosas. Atores afetados de forma semelhante pela política regulatória podem formar coalizões e lutar contra os atores com interesses diferentes dos seus. Smith chama este tipo de política de "conflitiva" (conflicting issues). Elas provocam um alto grau de interesse em várias empresas. As empresas muito interessadas na questão dividem-se em relação à proposta: algumas a favorecem; outras a contrariam. Neste caso, portanto, os interesses são diferentes e conflitantes. Decisões deste tipo também precisam ser investigadas.

As políticas redistributivas afetam a alocação da propriedade, da riqueza ou da renda. O efeito das políticas redistributivas pode atingir igualmente toda uma classe social - de um lado, a classe dos money providers; de outro lado, a classe dos service demanders. É o que ocorre, por exemplo, quando institui-se a tributação progressiva ou um imposto sobre grandes fortunas. Smith considera que as políticas redistributivas geralmente são políticas "unificantes" (unifying issues), pois: (i) despertam um grau elevado de interesse entre muitas empresas; (ii) a maioria significativa das empresas interessadas compartilha a mesma posição. Neste caso, os interesses empresariais usualmente são semelhantes. Assim como as políticas regulatórias - às vezes, ainda mais do que aquelas -, as políticas redistributivas tendem a gerar rela- 
ções conflituosas entre os interesses implicados. Mas os interesses empresariais, habitualmente, estão reunidos no mesmo lado do conflito.

Há muito espaço para pesquisas sobre a atividade política empresarial com vista aos diversos tipos de decisões.

\section{III.4. Momentos da ação política}

A ação política do empresariado distribui-se ao longo de diversos momentos e, em todos eles, merece ser atentamente pesquisada.

A ação empresarial remonta ao momento em que é feita a escolha dos indivíduos que participarão na tomada de decisões, pelo lado do setor público $^{8}$. Uma maneira de intervir nesta escolha é atuar junto aos partidos políticos quando estes definem os candidatos que lançarão às eleições para os cargos do Executivo e do Legislativo, nas esferas federal, estadual e municipal. Nesta ocasião, o empresariado tem duas opções: apoiar candidatos oriundos de suas próprias fileiras e/ou defender candidatos afinados com as suas posições. Vale a pena lembrar, como exemplo, que José Alencar Gomes da Silva, eleito Vice-Presidente da República pelo Partido Liberal de Minas Gerais (hoje no Partido Republicano Brasileiro do mesmo estado), é um grande empresário da indústria têxtil. Além disso, os três últimos ocupantes da Presidência da Confederação Nacional da Indústria são (ou foram) membros do Poder Legislativo federal: o ex-Presidente Carlos Eduardo Moreira Ferreira foi Deputado Federal pelo Partido da Frente Liberal (PFL) de São Paulo, na legislatura 19992003; o ex-Presidente Fernando Luiz Gonçalves Bezerra foi Senador pelo Partido Trabalhista Brasileiro (PTB) do Rio Grande do Norte, entre 1999 e 2007; o atual Presidente, Armando de Queiroz Monteiro Neto, é Deputado Federal pelo Partido Trabalhista Brasileiro (PTB) de Pernambuco.

A contribuição para campanhas eleitorais é outra maneira pela qual os empresários intervêm na escolha dos indivíduos que participam na tomada de decisões. No Brasil, as entidades de classe e as entidades sindicais são proibidas de oferecer contribuições de campanha para partidos políti-

\footnotetext{
8 Alguns indivíduos que participam das decisões pelo lado do setor público são selecionados mediante concurso. Neste caso, a intervenção do setor privado no processo de escolha é mais difícil.
}

cos ou candidatos a cargos eletivos (Lei n. 9 504/ 97, artigo 24, inciso VI). Por essa razão, as contribuições de campanha são um instrumento disponível para os empresários em base individual, assim como para suas empresas. A contribuição para campanhas eleitorais é um assunto amplamente explorado pela literatura internacional sobre a atuação política do empresariado. Em contraste, a questão das contribuições de campanha ainda é pouco estudada no país, apesar da grande relevância do tema e do esforço notável de alguns pesquisadores (há uma coletânea de estudos acadêmicos sobre financiamento de campanhas eleitorais em TRANSPARÊNCIA BRASIL, s/d). A escassez de trabalhos sobre a matéria no Brasil está associada à pobreza dos dados disponíveis. Existe uma convicção generalizada de que as informações prestadas pelos partidos políticos aos tribunais eleitorais são pouco confiáveis. O progresso do conhecimento neste campo depende de mais e melhores informações sobre as fontes de recursos de partidos e candidatos, o que, por sua vez, depende do aperfeiçoamento da legislação sobre financiamento de campanhas eleitorais, assim como do aprimoramento da fiscalização.

Além de apontar candidatos a cargos eletivos e contribuir para campanhas eleitorais, os empresários também sugerem ou vetam nomes para cargos de indicação em ministérios, secretarias, fundações, autarquias, empresas estatais, instituições públicas de financiamento da produção (por exemplo, Banco do Brasil, Banco Nacional de Desenvolvimento Econômico e Social etc.), agências reguladoras etc.

Uma vez definidos os participantes do processo de tomada de decisão, novos momentos abremse para a ação política do empresariado. Estes momentos correspondem aos estágios que formam o ciclo decisório propriamente dito ${ }^{9}$. Estes estágios variam de acordo com as instâncias em que as decisões são tomadas. Quando a instância é, por exemplo, o Poder Legislativo federal, o ciclo decisório abrange os seguintes estágios: a formulação das proposições analisadas pelo parlamento; a discussão das proposições no âmbito das

\footnotetext{
9 Howlett e Ramesh (2003) sugerem que o ciclo decisório das políticas públicas seja analiticamente dividido em cinco estágios: formação da agenda; formulação; tomada de decisão; implementação; avaliação.
} 
comissões e/ou do plenário da Câmara dos Deputados ou do Senado Federal; a votação das proposições discutidas; dependendo do tipo de proposição, o pronunciamento do Presidente da República sobre o texto aprovado, assim como a votação dos parlamentares sobre vetos eventualmente interpostos pelo presidente. A articulação dos interesses empresariais pode ocorrer em qualquer um dos estágios mencionados da produção legislativa.

A ação política do empresariado também estende-se ao momento que sucede a tomada de decisão propriamente dita. Em primeiro lugar, é muito comum a mobilização dos empresários para intervir na fase de regulamentação ou implementação das decisões tomadas. A regulamentação usualmente é feita por meio de atos, portarias, circulares, notas técnicas e vários outros mecanismos à disposição da burocracia do Poder Executivo. Em segundo lugar, sempre existe a possibilidade de recurso ao Poder Judiciário, quando o segmento considera uma decisão lesiva aos seus direitos.

Por todo o exposto, torna-se patente que a ação do empresariado é multifacetada, e distribui-se ao longo de diversos momentos relevantes. Pesquisas de grande interesse podem investigar a atuação empresarial em vários desses momentos ou concentrar a atenção em algum deles, especificamente.

\section{III.5. Forma da ação política}

A interação de empresários com o setor público pode assumir uma forma degenerada. É o que acontece quando está em jogo a obtenção de vantagens ilícitas para ambas as partes; quando empresários concedem dinheiro e/ou outros benefícios aos tomadores de decisão, em troca de diversos tipos de recompensas ilegais. Naturalmente, detectar e investigar episódios como esses, assim como punir os seus culpados, são atitudes da maior importância para a defesa do interesse público. A mídia brasileira tem oferecido uma contribuição valiosa neste sentido, ao denunciar e acompanhar diariamente numerosos eventos de corrupção. No entanto, a análise da interação ilícita entre empresários e o setor público não precisa ser monopólio dos jornalistas. Os cientistas sociais podem tratar deste fenômeno em suas pesquisas.

Por outro lado, a parcela não-ilegal da interação público-privado também oferece um terreno fertilíssimo para a investigação acadêmica, um terreno muito mais acessível e que ainda permanece relativamente inexplorado.

A Tabela 3 apresenta alguns exemplos de atividades que podem ser realizadas pelos empresários em defesa dos seus interesses. O estudo das técnicas, táticas e estratégias empresariais de ação política é mais um campo aberto para os pesquisadores.

\section{TABELA 3 - POSSÍVEIS AÇÕES DOS EMPRESÁRIOS EM DEFESA DE SEUS INTERESSES}

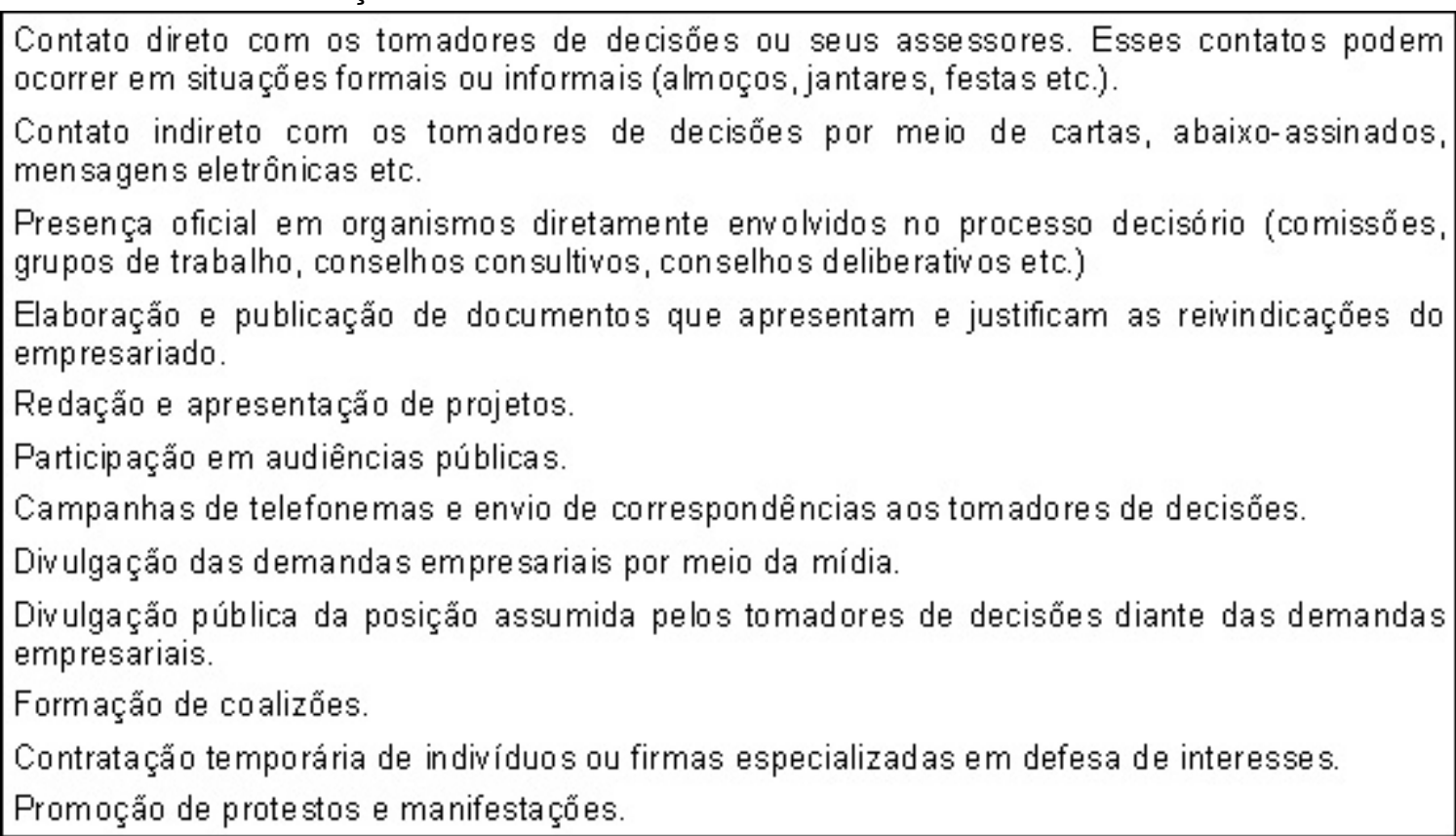
Promoçẫo de protestos e manifestaçốes.

FONTE: o autor. 


\section{III.6. Fins e resultados da ação política}

Basicamente, a atuação política do empresariado pode visar a dois fins opostos: em primeiro lugar, mudar o status quo para melhor, tanto quanto possível (atitude ofensiva). Em se- gundo lugar, impedir a piora do status quo, tanto quanto possível (atitude defensiva).

Assim, as decisões do setor público podem ser classificadas em quatro categorias, do ponto de vista dos agentes privados, como mostra a Tabela 4.

TABELA 4 - DECISÕES E STATUS QUO

\begin{tabular}{|l|c|c}
\hline IMPAC TO SOBRE STATUS QUO & \multicolumn{2}{|c}{ RESULTADO DA DECISÄO } \\
\cline { 2 - 3 } & SUCESSO & INSUCESSO \\
\hline Status quo muda & Ganho & Perda \\
Status quo mantémse & Alívio & Frustracẫo \\
\hline FONTE: o autor. &
\end{tabular}

Um sucesso político pode ser definido como a convergência entre o teor da decisão e a posição empresarial. Por sua vez, um insucesso consiste na divergência entre o teor da decisão e a posição empresarial.

O empresariado pode colher dois tipos diferentes de sucesso. O ganho ocorre quando o empresariado postula uma decisão que muda o status quo para melhor, e esta decisão é tomada pelo setor público. $\mathrm{O}$ alívio ocorre quando o empresariado opõe-se a uma decisão que levaria à piora do status quo, e esta decisão não é tomada.

Por outro lado, os empresários também podem colher dois tipos diferentes de insucesso. A perda acontece quando o empresário luta contra uma decisão que mudará o status quo para pior, mas a decisão é tomada mesmo assim. A frustração é um tipo de insucesso político que ocorre quando o empresariado defende uma decisão que mudaria o status quo para melhor, mas a decisão não é tomada.

Os indicadores de sucesso político utilizáveis em pesquisas empíricas podem ser classificados em dois tipos: os indicadores baseados em impressões e os indicadores baseados em resulta$\operatorname{dos}^{10}$.

No caso dos indicadores baseados em impressões, o pesquisador pode empregar três fontes diferentes de informação. Pode utilizar, por exemplo, a avaliação que o empresário faz a respeito de

10 Uma ampla discussão sobre esse tópico pode ser encontrada no terceiro capítulo de nosso livro (MANCUSO, 2007). seu próprio sucesso em episódios de decisão política. Ele também pode recorrer à avaliação do tomador de decisão sobre o grau de sucesso obtido pelo empresariado. O pesquisador pode ainda usar como indicador de sucesso a avaliação que é feita por observadores experientes e familiarizados com o contexto em que as decisões ocorrem. Nas três circunstâncias, ele relata a avaliação que é feita por outros indivíduos.

No caso dos indicadores baseados em resultados, o papel reservado para o pesquisador é muito maior. Para apontar a presença ou a ausência de sucesso político, o pesquisador verifica o conteúdo efetivo da deliberação tomada e o coteja com a posição empresarial, em vez de valer-se simplesmente das impressões manifestadas pelo próprio ator, pelo tomador de decisão ou por experts.

Mensurar o grau de sucesso político do empresariado e avaliar o tipo predominante de sucesso (ou insucesso) são desafios fascinantes que colocam-se para os cientistas sociais. Pesquisas que encarem esses desafios podem proporcionar uma resposta empiricamente fundamentada para uma questão central da literatura sobre a relação entre o empresariado e o poder público em democracias capitalistas: o empresariado realmente ocupa uma posição política privilegiada, em decorrência da dependência estrutural do Estado, e da sociedade como um todo, em relação ao capital (MILIBAND, 1969; 1989; LINDBLOM \& DAHL, 1976; LINDBLOM, 1977; 1980; 2001; OFFE \& WIESENTHAL, 1984; PRZEWORSKI \& WALLERSTEIN, 1988)? Ou tal supremacia não existe, podendo o poder político do empresariado variar de caso para caso, ao longo do tempo e de 
um lugar para o outro (VOGEL, 1987; 1989; 1996)?

\section{COMENTÁRIOS FINAIS}

Ao iniciar o seu trabalho, um pesquisador decidido a estudar a ação política do empresariado no Brasil enfrenta, simultaneamente, dois grandes desafios: em primeiro lugar, conhecer o que foi feito até então pelos colegas que o antecederam; em segundo lugar, definir o perfil de sua própria pesquisa, de modo a situá-la diante do conhecimento que já foi produzido.

Este artigo oferece uma contribuição em ambas as frentes. A Tabela 1, apresentada na primeira seção, reconstitui e sintetiza um longo debate, travado há décadas, acerca da força (ou fraqueza) política do empresariado que atua no país. Portanto, a primeira seção do artigo recorta a vasta literatura existente, focalizando as obras referentes ao debate mencionado e propondo uma inter- pretação deste debate. Como foi dito, a seção não aborda toda a literatura relevante. Além disso, podem ser propostas outras interpretações para o mesmo debate. Apesar destes limites, a primeira seção pode ser útil para orientar o investigador interessado em dirigir seus esforços para o enriquecimento desta discussão.

Por sua vez, a Tabela 2 apresentada na segunda seção, identifica questões utilizáveis para determinar a natureza de novas pesquisas sobre o tema. Essa tabela também proporciona possíveis respostas para as questões cruciais que foram levantadas. Desta forma, a segunda seção do artigo aponta uma série de caminhos promissores para novos estudos empíricos sobre a atuação política empresarial.

A mensagem deste artigo pode, então, ser resumida da seguinte maneira: nosso campo de estudos possui uma história respeitável e, hoje, continua bem vivo, em expansão!

Wagner Pralon Mancuso (pralon@usp.br) é Doutor em Ciência Política pela Universidade de São Paulo (USP) e Professor do Curso de Gestão de Política da mesma instituição.

\section{REFERÊNCIAS BIBLIOGRÁFICAS}

BIELCHOWSKY, R. 2000. Pensamento econômico brasileiro : o ciclo ideológico do desenvolvimentismo. $4^{\mathrm{a}}$ ed. Rio de Janeiro : Contraponto.

BRESSER-PEREIRA, L. C. 1974. Empresários e administradores no Brasil. São Paulo : Brasiliense.

CARDOSO, F. H. 1965. Hegemonia burguesa e independência econômica : raízes estruturais da crise política brasileira. In : FURTADO, C. (org.). 1968. Brasil : tempos modernos. Rio de Janeiro : Civilização Brasileira.

1971. Política e desenvolvimento em sociedades dependentes : ideologias do empresariado industrial argentino e brasileiro. Rio de Janeiro : Zahar.

1972. Empresário industrial e desenvolvimento econômico no Brasil. São Paulo : Difusão Européia do Livro.

1975. Autoritarismo e democratização. Rio de Janeiro : Paz e Terra.
CRUZ, S. V. 1978. Empresários e o regime no Brasil : a campanha contra a estatização. São Paulo. Tese (doutorado em Ciência Política). Universidade de São Paulo.

DINIZ, E. 1992. Neoliberalismo e corporativismo : as duas faces do capitalismo industrial no Brasil. Revista Brasileira de Ciências Sociais, Rio de Janeiro, ano 7, n. 20, p. 31-46.

DINIZ, E. \& BOSCHI, R. 1978. Empresariado nacional e Estado no Brasil. Rio de Janeiro : Forense Universitária.

1979. Autonomia e dependência na representação dos interesses industriais. Dados, Rio de Janeiro, n. 22, p. 25-48.

1993. Lideranças empresariais e problemas da estratégia liberal no Brasil. Revista Brasileira de Ciências Sociais, Rio de Janeiro, n. 23, 101-119.

1997. O Legislativo como arena de interesses organizados : a atuação dos lobbies empresariais. Digit. 
DOCTOR, M. 2002. Business and Delays in Port Reform in Brazil. Revista Brasileira de Economia Política, v. 22, n. 2, p. 79-86, abr.-jun. Disponível em : http://www.rep.org.br/pdf/865.pdf. Acesso em : 16.abr.2007.

DREIFUSS, R. A. 1981. 1964 : a conquista do Estado. Petrópolis : Vozes.

1989. O jogo da direita na Nova República. Petrópolis : Vozes.

FERNANDES, F. 1976. A revolução burguesa no Brasil : ensaio de interpretação sociológica. Rio de Janeiro : Zahar.

FURTADO, C. 1965. Obstáculos políticos ao crescimento econômico no Brasil. Revista Civilização Brasileira, Rio de Janeiro, v. 1, n. 1.

HARDIN, R. 1982. Collective Action. Baltimore : Johns Hopkins University.

HOWLETT, M. \& RAMESH, M. 2003. Studying Public Policy : Policy Cycles and Policy Subsystems. Toronto : Oxford University.

KINGSTONE, P. 2001. Re-Inventing Business : Commercial Liberalization and the Response of Industrialists in Brazil. Trabalho apresentado na conferência Reforming Brazil, Bildner Center for Western Hemisphere Studies, City College of New York.

LEOPOLDI, M. A. P. 1984. Industrial Associations and Politics in Contemporary Brazil (1930-1961). Tese (Doutorado em Ciência Política). Universidade de Oxford.

LINDBLOM, C. E. 1977. Politics and Markets. New York : Basic.

1980. O processo de decisão política. Brasília: UNB

2001. The Market System : What It Is, How It Works, and What To Make of It. New Haven : Yale University.

LINDBLOM, C. \& DAHL, R. 1976. Politics, Economics and Welfare. Chicago : University of Chicago.

LOWI, T. 1964. American Business, Public Policy Case-Studies, and Political Theory. World Politics, Baltimore, v. 16, n. 4, p. 677-715, July.

MANCUSO, W. P. 2004. O lobby da indústria no Congresso Nacional : empresariado e política no Brasil contemporâneo. Dados, Rio de Janeiro, v. 47, n. 3, p. 505-547. Disponível em : http://www.scielo.br/pdf/dados/v47n3/ a03v47n3.pdf. Acesso em : 16.abr.2007.

2007. O lobby da indústria no Congresso Nacional : empresariado e política no Brasil contemporâneo. São Paulo : USP.

MANCUSO, W. P. \& OLIVEIRA, A. J. S. N. 2006. Abertura econômica, empresariado e política : os planos doméstico e internacional. Lua Nova, São Paulo, n. 69, p. 147-172. Disponível em : http://www.scielo.br/pdf/ln/n69/ a07n69.pdf. Acesso em : 16.abr.2007.

MARTINS, L. 1968. Industrialização, burguesia nacional e desenvolvimento. Rio de Janeiro : Saga.

MATTOS, H. J. G. 1958. O problema do desenvolvimento econômico e a burguesia nacional. São Paulo : Federação das Indústrias do Estado de São Paulo.

MILIBAND, R. 1969. The State in Capitalist Society. New York : Basic.

1989. Divided Societies : Class Struggle in Contemporary Capitalism. Oxford : Clarendon.

MOE, T. M. 1988. The Organization of Interests. Chicago : University of Chicago.

OFFE, C. \& WIESENTHAL, H. 1984. As duas lógicas da ação coletiva : anotações teóricas sobre classe social e forma organizacional. In : OFFE, C. (org.). Problemas estruturais do Estado capitalista. Rio de Janeiro : Tempo Brasileiro.

OLIVEIRA, A. J. S. N. 2003. O papel da coalizão empresarial brasileira e as negociações da ALCA. São Paulo. Tese (doutorado em Ciência Política). Universidade de São Paulo.

PAYNE, L. 1994. Brazilian Industrialists and Democratic Change. Baltimore: Johns Hopkins University.

POWER, T. \& DOCTOR, M. 2002. The Resilience of Corporatism : Continuity and Change in Brazilian Corporatist Structures. Oxford : Centro de Estudos Brasileiros.

PRADO JÚNIOR, C. 1966. A revolução brasileira. São Paulo : Brasiliense. 
PRZEWORSKI, A. \& WALLERSTEIN, M. 1988. Structural Dependence of the State on Capital. American Political Science Review, London, v. 82, n. 1, p. 11-29, Mar.

SCHNEIDER, B. R. 1997a. Big Business and Constitutional Reform in Brazil. Artigo apresentado na conferência Estrutura de Poder, Intermediação de Interesses e Elaboração de Políticas : Perspectivas para a Reforma do Estado no Brasil, Instituto de Estudos LatinoAmericanos da Universidade de Londres.

1997b. Big Business and the Politics of Economic Reform : Confidence and Concertation in Brazil and Mexico. In : SCHNEIDER, B. R. \& MAXFIELD, S. (eds.). Business and the State in Developing Countries. Ithaca : Cornell University.

1998. The State and Collective Action : Business Politics in Latin America. Trabalho apresentado no encontro da Latin American Studies Association, realizado em Chicago.

2002. Some Consequences of Business Organization for Development and Democracy in Latin America. Trabalho apresentado no workshop Changing Nature of Business-State Relations in Brazil : Strategies of Foreign and Domestic Capital, St. Anthony's College. Relatório do workshop.

2004. Business Politics and the State in Twentieth-Century Latin America. New York : Cambridge University.

SMITH, M. A. 2000. American Business and Political Power : Public Opinion, Elections, and Democracy. Chicago : The University of Chicago.

SODRÉ, N. W. 1958. O problema da burguesia. In :__. Introdução à revolução brasileira. Rio de Janeiro : J. Olympio.

TULLOCK, G. 1993. Rent Seeking. London : E. Elgar.

VOGEL, D. 1987. Political science and the study of corporate power : a dissent from the new conventional wisdom. British Journal of Political Science, v. 17, n. 4, p. 385-408, Oct.

1989. Fluctuating Fortunes : The Political Power of Business in America. New York : Basic.

1996. Kindred Strangers : The Uneasy Relationship between Politics and Business in America. New Jersey : Princeton University.

WEYLAND, K. 1998a. The Fragmentation of the Business in Brazil. In : DURAND, F. \& SILVA, E. (eds.). Organized Business, Economic Change, and Democracy in Latin America. Miami : North-South Center.

1998b. From Leviathan to Gulliver? The Decline of Developmental State in Brazil. Governance, London, v. 11, n. 1, p. 51-75, Jan.

2001. Brazilian Business and Market Reform : A Mixed Record. Trabalho apresentado no workshop The Brazilian Automotive Industry : Foreign Direct Investment and Business-State Relations, St. Anthony’s College. Relatório do workshop.

\section{OUTRAFONTE}

TRANSPARÊNCIA BRASIL. s/d. http:// www.transparencia.org.br. 
THE ENTREPRENEURIAL SECTOR AS A POLITICAL ACTOR IN BRAZIL: AN INVENTORY OF THE LITERATURE AND A RESEARCH AGENDA

\section{Wagner Pralon Mancuso}

This article presents, in the first place, an inventory of academic production on the entrepreneurial sector as a political actor in Brazil. We intend to argue that since the early 1950s and until the present, an important part of this literature is centered around a fundamental debate: whether the Brazilian entrepreneurial class should be considered a "weak" or a "strong" political actor. In the second place, we propose a research agenda on the issue. For such purposes, we raise issues that, when taken together, provide a wide-ranging script for study on the topic. In expounding this script, we identify elements that can be explored by the community of social scientists that have interest in the issue.

KEYWORDS: entrepreneurial sector; bourgeoisie; corporatism. 
L'ENTREPRENEUR COMME ACTEUR POLITIQUE AU BRÉSIL: FAIRE LE POINT SUR LA LITTÉRATURE ET LES PROJETS DE RECHERCHE

\section{Wagner Pralon Mancuso}

D’abord, cet article fait le point sur la production académique concernant l'entrepreneur comme acteur politique au Brésil. D’abord, depuis les années 1950 jusqu'à nos jours, une part importante de cette littérature est centrée sur une question essentielle : l'entrepreneur qui opère au Brésil est-il un acteur «fort» ou «faible»? Ensuite, cet article propose un agenda de recherches sur le thème. A cet effet, il soulève des questions qui, globalement, forment un important scénario pour l'étude de cette matière. L’exposé de ce scénario servira à identifier des éléments pouvant être exploités par la communauté de scientifiques sociaux qui s’y intéressent.

MOTS-CLÉS: entrepreneurs; bourgeoisie; pouvoir; corporativisme. 